\title{
Periodic Acid Schiff (PAS) Staining: A Useful Technique for Demonstration of Carbohydrates
}

\author{
Swapna Shedge A. ${ }^{1}$, Priya Roy ${ }^{2}$, Ajay Shedge ${ }^{3}$, Megha A. Doshi ${ }^{4}$ \\ ${ }^{1}$ Assistant Professor Department of Anatomy, ${ }^{2}$ Associate Professor, Department of Anatomy, ${ }^{3}$ Assistant Professor, \\ Department of Pathology, ${ }^{4}$ Professor and Head, Department of Anatomy, KIMS, Deemed to be University,
} Karad, Maharashtra

\begin{abstract}
The term mucosubstances is used to denote all tissue components other than glycogen, rich in carbohydrates, which are present in connective tissue or as secretion of certain epithelial structures. Connective tissue mucosubstances are called "mucopolysaccharides", while those secreted by epithelia are referred as "mucins".

Objectives: To show the usefulness of PAS staining in identification of carbohydrates in normal and malignant lesions of mammary gland and endocervical gland .

Methodology: This is a retrospective, observational, analytical, case control study aimed to evaluate mucin histochemical pattern in normaland diseased lesions of mammary and endocervical glands. Twenty five histologically proven blocks of normal and Intraductal carcinoma of mammary gland, normal and adenocarcinoma of endocervical glands were taken. Tissue sections were stained by PAS technique.

Results: Results were tabulated according to colour intensity into different grades ranging from + to ++++ . PAS staining of normal endocervical glands showed presence of PAS +ve substances like carbohydrate $\&$ mucins. PAS stain for adenocarcinoma cervix gave mild reaction with focal magenta shade, suggestive of presence of few neutral mucosubstances. PAS staining of normal mammary gland and of Intraductal carcinoma showed similar results. Ducts and lobules stained with magenta showed the presence of PAS positive substances like carbohydrate and neutral mucins.

Conclusion: Mucin histochemical patterns serve as valuable, cost-effective tool for diagnosis in histopathology and for the researchers in histology, where a slight change in the mucin pattern may help in the early diagnosis of disease process. PAS technique is perhaps the most versatile and widely used of techniques for the demonstration of glycoproteins, carbohydrates and mucins.
\end{abstract}

Keywords: Mucins, PAS stain, Normal, Adenocarcinoma, Intraductal carcinoma.

\section{Introduction}

Special stains belong to a diverse family of slide-

\section{Corresponding Author:}

Priya P. Roy

Associate Prof., Department of Anatomy, Krishna

Institute of Medical Sciences, Deemed to be University,

Karad, Maharashtra

e-mail: priyaproy4@gmail.com

Cell No.: +91-9970117336 based stains that rely on basic chemical reactions for microscopic visualization and general identification of various tissues, structures, cells, organelles, carbohydrates, minerals and micro-organisms. Introduced to all college biology students through the simple bacterial test known as the Gram stain. Special stains use both, science and art to provide valuable and cost-effective information for pathology laboratory. ${ }^{1}$

Periodic acid $\left(\mathrm{HlO}_{4}\right)$ is an oxidizing agent used initially by Jackson and Hudson (1937) for the chemical estimation of polysaccharides. "McManus" (1946) 
was the first to apply Periodic acid to the histological demonstration of mucin, whereas Hochkiss (1948) emphasized the legitimacy of Periodic acid as a special histochemical reagent. ${ }^{2}$ Dr. Joseph Forde Anthony McManus (1911-1980) was a Canadian pathologist who is best known for his formulation of one of the most frequently used stains in histopathology; the McManus Periodic-acid Schiff stain ${ }^{3}$. Periodic acid acts upon the 1.2 glycol linkage of carbohydrates in tissue sections to produce aldehyde which can be colored with Schiff's reagent. The method can be used in paraffin sections or frozen sections and is useful as a reaction for carbohydrates of tissue: i.e glycogen (in paraffin sections only) mucin, basement membrane, reticulin, colloid of thyroid and pituitary stalk, granular cells of renal arteriole etc. ${ }^{4}$

Chemistry ${ }^{5,6}$ PAS reaction demonstrates aldehyde groups formed by the oxidation of certain tissue carbohydrates and glycogen. The oxidation of the tissue sections is performed using periodic acid. After oxidation, tissue sections are treated with Schiff's reagent, a colourless mixture of basic fuchsin, $\mathrm{HCl}$ and sodium metabisulfite. During incubation, basic fuchsin binds to the newly formed aldehyde groups in the tissue. Rinsing the sections in running water after the Schiff reagent incubation causes the bound basic fuchsin molecules to assume a pink to red color due to molecular changes. Several counter stains may then be used to visualize other tissue elements. Hematoxylin counterstaining is very commonly used to demonstrate cell nuclei, although other counterstains may also be used. Some older method include treating the sections in a sulfurous rinse solution before running water wash. This can serve to reduce background staining by removing excess Schiff's reagent from the tissue. 5,6

\section{Material and Method}

The present study was conducted in the Department of Anatomy,Krishna Institute of Medical Sciences University, Karad from May 2010 to June 2018. The type of study was observational, analytical and case control. Work protocol was submitted to the protocol and ethical committee for approval and necessary permission was taken.

Sample size was twenty five blocks of histologically proven normal and Intraductal carcinoma of mammary gland, normal and adenocarcinoma of endocervical glands. The tissues were fixed in $10 \%$ formal saline with $2 \%$ calcium acetate and a pinch of phosphotungstic acid to help for preservation of mucins. The tissues embedded in paraffin blocks were prepared by histopathological technique and cut at 5-6 microns. Sections were stained with Hematoxylin and Eosin for identification of the tissue and special stain PAS for identification of carbohydrates and results were interpreted. P.A.SPeriodic acid Schiff reagent stains all carbohydrates including mucosubstances. Therefore mucosubstances are P.A.S. positive. All the results obtained were tabulated according to colour intensity into different grades ranging from + to $++++.7,8,9$

\section{Observations and Results}

All the results were tabulated according to colour intensity into different grades ranging from + to $++++.7,8,9$

\section{Colour Index:}

++++ : Very strong positive reaction.

+++ : Strong positive reaction.

$+\quad$ : Moderate reaction.

$+\quad$ : Weak reaction.

: Negative reaction.

Table Showing Histochemical result for PAS stain.

\begin{tabular}{|c|l|l|l|}
\hline Sr.No. & Tissue stained & Result & Inference about Mucosubstances \\
\hline 1 & Normal endocervical glands Photomicrograph 1 & +++ & $\begin{array}{l}\text { PAS +vesubstances like } \\
\text { carbohydrate \& mucins present. }\end{array}$ \\
\hline 2 & $\begin{array}{l}\text { Adenocarcinoma endocervical glands } \\
\text { Photomicrograph 2 }\end{array}$ & ++ & $\begin{array}{l}\text { PAS +ve } \\
\text { Substances Present }\end{array}$ \\
\hline 3 & Normal mammary gland Photomicrograph 3 & $\begin{array}{l}++ \text { (Duct cells, Duct lumen, } \\
\text { Lobule cells and Lobule lumen) }\end{array}$ & $\begin{array}{l}\text { PAS +ve } \\
\text { Substances Present }\end{array}$ \\
\hline 4 & Intraductal carcinoma breast Photomicrograph 4 & ++ & $\begin{array}{l}\text { PAS positive mucosubstances } \\
\text { present. }\end{array}$ \\
\hline
\end{tabular}


Inference: Regarding special stains - PAS stain was used to assess presence of neutral mucosubstances. PAS stain for normal endocervix gave magenta colour with strong reactivity suggestive of presence of netural mucin. Epithelium and glands, both gave moderate to strong reactivity. PAS stain for adenocarcinoma cervix gave mild reaction as focal magenta staining, suggestive of presence of minimal neutral mucosubstances as compared to normal endocervix.
Sections of normal mammary gland stained with PAS showed the ducts and lobules stained magenta, confirming the presence of PAS positive substances like carbohydrate and neutral mucins. For Intraductal carcinoma breast, PAS stain gave moderate reaction as focal magenta staining, suggestive of presence of neutral mucosubstances. However the colour intensity was more than that of normal breast tissue.

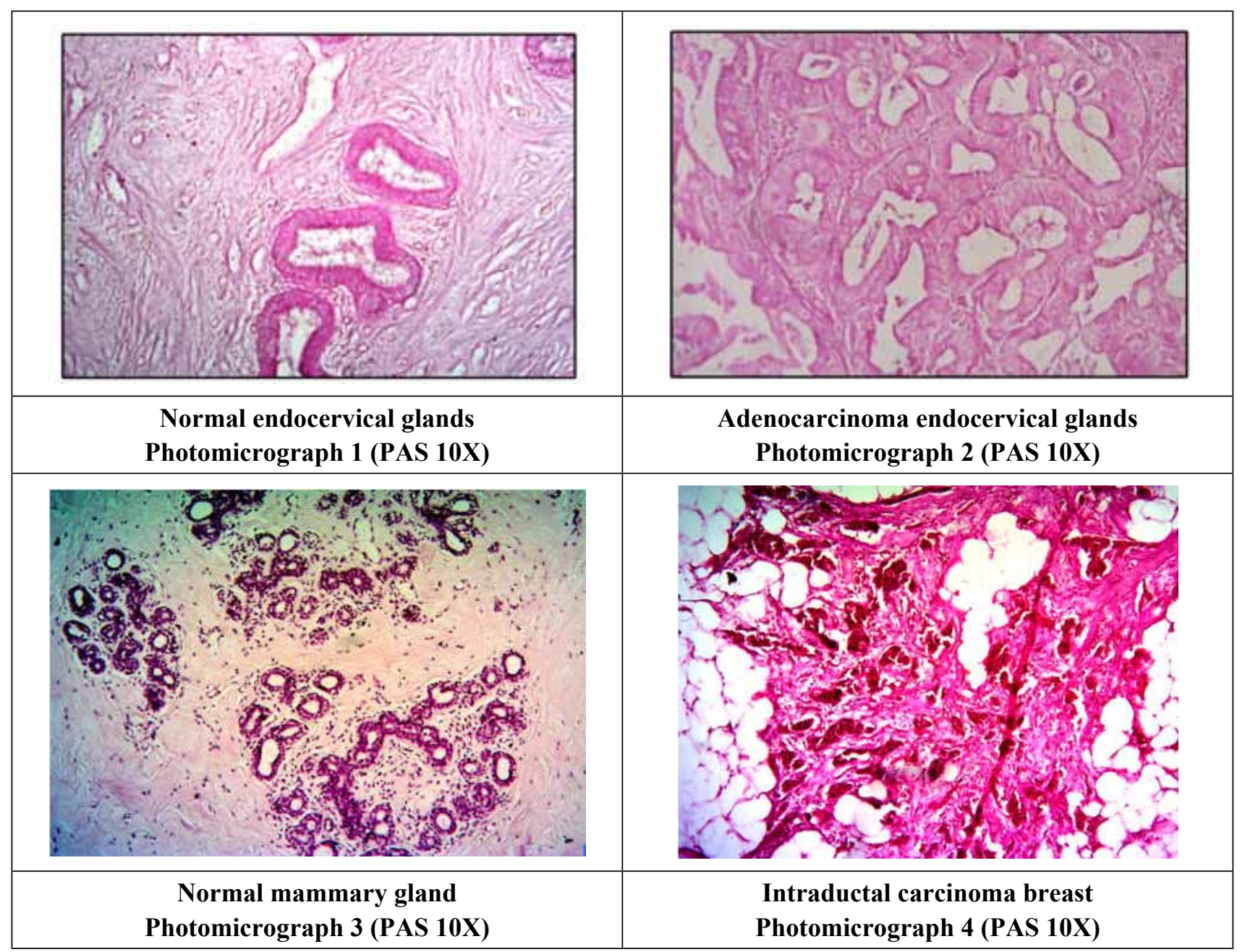

\section{Discussion}

Worldwide, cervical cancer is the fifth most deadly cancer in women ${ }^{10}$. It affects about 16 per 100,000 women per year ${ }^{11}$. It accounts for $20-25 \%$ of all the cancers and $85 \%$ of all the female genital tract malignancies. Primary adenocarcinomas make 5-10\% of all cancers of the cervix ${ }^{12}$. Invasive breast cancer is the most common carcinoma in women, accounting for $23 \%$ of all cancers in women globally ${ }^{13}$ and now the most common cancer in Indian women, having recently overtaken cervical cancer in this respect. ${ }^{14}$

The term "mucosubstances" is used to denote all tissue components, other than glycogen, rich in carbohydrates which are present in connective tissue or as secretion of certain epithelial structures by Spicer et al. ${ }^{15,16}$

Numerous types of mucins occur depending on the 
site of production. Examples of connective tissue mucins are chondroitin sulphate, heparin sulphate, keratin sulphate and hyaluronic acid. Epithelial mucins may be neutral or acidic. Neutral mucins are hexosamine units which may be associated with glucoronic or sialic acid; the reactive group being carboxyl. In sulphated mucins this group is blocked by a sulphate group which becomes the active group ${ }^{17}$. Strongly sulphated mucins are of connective tissue type; the weakly sulphated groups are of epithelial type. The non-sulphated mucins are sialic acid and hyaluronic acid (carboxylated D-glucoronic acid). These can be enzymatically digested, though enzyme resistant forms do occur. ${ }^{17}$

With the development of new histochemical method by special stains, specific chemical composition of mucosubstances is documented by various scientists. But there have been very few studies on human endocervical mucosubstances such as by J. N. Bulmer et al $(1988)^{18}$, Vatsala Misra et al (1997) ${ }^{19}$, Zhao Shumei et al $(2003)^{20}$ and Hayashi, Isamu M.T et al (2003) $)^{21}$ and human mammary gland by Luciano Ozzello and Speer (1958) ${ }^{22}$,D J Cooper (1974) $)^{17}$, Muaz Osman Fagare (2015) ${ }^{23}$ and S S.Spicer et al $(2016)^{24}$. The PAS reacton is an useful indicator of the presence of tissue carbohydrates, and particularly so for glycogen when the technique incorporates a diastase digestion stage. ${ }^{25,26}$

\section{Summary and Conclusion}

Mucin histochemistry of normal and malignant endocervical glands, normal and Intraductal carcinoma of breast was undertaken in the department of Anatomy at Krishna Institute of Medical Sciences University, Karad from 2010 to 2018.

In the present study, Haematoxylin and Eosin was used as routine stain for identification and confirmation of the tissue and special staining with PAS was carried out for presence of carbohydrates.

- In the present study mucin histochemistry of normal endocervical glands showed mixture of mucosubstances, both neutral and acidic.

- Histochemical results for malignant endocervical glands showed very few mucins. Mixture of both neutral and acidic were found. Neutral mucins were in trace amounts. So there is a shift in mucin pattern as compared to normal.

- Mucin histochemistry of normal breast tissue showed that neutral as well as acidic mucins were present.

- Histochemical results for IDC breast showed a mixture of both neutral as well as acidic mucins, with predominance of neutral mucins.

- The present study correlates well with workers like, J. N. Bulmer et al (1988) $)^{18}$, Vatsala Misra et al $(1997)^{19}$, Zhao Shumei et al $(2003)^{20}$ and Hayashi, Isamu M.T et al (2003) $)^{21}$ in the histochemical study of normal and adenocarcinoma of endocervix gland.

- In the histochemical study of normal and neoplastic breast,the present study correlates well with workers, Luciano Ozzello and Speer (1958) ${ }^{22}$, D J Cooper (1974) ${ }^{17}$, Muaz Osman Fagare $(2015)^{23}$ and S S.Spicer et al (2016) ${ }^{24}$

Ethical Clearance: Institutional Ethics Committee KIMS "Deemed to be University”, Karad.

Source of Funding: Institutional Ethics Committee KIMS “Deemed to be University", Karad.

Conflict of Interest: None.

\section{References}

1. Carson FL. Histotechnology: A self-instructional text. 2nd ed. Chicago: ASCP Press; 1997.

2. Jass JR. Mucin staining. Origins of mucin staining. Jr Clin. Pathol. 1996; 787-90.

3. McMannus JFA. Histological demonstration of mucin after Periodic Acid. Nature. 1946; 158:202.

4. McMannus JFA. Histological and Histochemical uses of Periodic Acid. Biotechnique and Histochemistry. 1948; 23 (3): 99-108.

5. National Society for Histotechnology. Carbohydrate stain reference manual. Lanham, MD: National Society for Histotechnology; 1989.

6. Bancroft JD, Stevens A, editors. Theory and practice of histological techniques. 4th ed. London: Churchill Livingstone; 1996. p. 173-211.

7. Stanforth DA. Staining method :Carbohydrates and Amyloid. In Wulff S. Guide to special stains. $1^{\text {st }}$ edition California:Dako; 2004:48-49..

8. Drury RAB, Wallington EA. The theory and practice of staining in Carleton's histological technique. $5^{\text {th }}$ ed. Oxford University Press, Great Britain. 1980 : 107-118.

9. Tock EP and Tan NT. A histochemical study of mucins of the adult human nasopharanyx. J. 
Anat.1969; 104(1): 81-92.

10. World Health Organization (Feb.2006), "Fact Sheet No.297: Cancer”. Retrieved; 2007-12-01.

11. GLOBOCAN 2002 Database: "Summary table by Cancer". Retrived 2008-10-26.

12. Carcinoma of the cervix in Shaw's text book of Gynaecology, $10^{\text {th }}$ edition, Ed. Padulidri V,Daftary SN,428-460,1989.

13. Colditz G, Chia K.S. Invasive breast carcinoma: Introduction and general features. WHO Classification of tumours of the breast, 4th ed, Lyon: IARC; 2012.pg 14.

14. Ghoncheh M, Momenimovahed Z, Salehiniya H. Epidemiology, incidence and mortality of breast cancer in Asia. Asian Pac J Cancer Prev. 2016;17:47-52.

15. .Spicer S.S, Leppi. T.J and Stoward. P.J. Suggestion of Histochemical terminology of carbohydrate rich tissue components. J. Histochem. Cytochem.1965; 13: 599-03

16.Tock EP and Tan NT. A histochemical study of mucins of the adult human nasopharanyx. J.Anat. 1969;104(1): 81-92.

17.Cooper DJ. Mucin histochemistry of mucous carcinoma of breast and colon and non-neoplastic breast epithelium. Jr Clin Pathol 1974; 27(4): 311-314.

18.JV Bulmer, N.R. Griffin, RE-Kingston, M Wells. Minimal Deviation Adenocarcinoma (adenoma malignum) of the endocervix; A histochemical and immunohistochemical study of 2 cases (Nov 1988) Gynecol Oncol.-Volume 36, Issue 1, January 1990, Pages 139-146

19.Vatsala misra, SC Gupta, Anjali Goel, PA Singh: Re-classification of carcinoma cervix uteri by mucin histochemistry; Indian J. pathol microbiol; 40(4): 4634681997.

20.Zhao Shumei, Hayasaka Tadashu, Osakabe, International journal of gynaecological pathology oct.2003 - vol 22 1ssue 4- pp 393-397)

21.Hayashi I, Tsuda H,Shimuda T.Reappraisal of orthodox histochemistry for the diagnosis of minimal deviation adenocarcinoma of cervix. J Surgical Pathol 2008, 24:559-562.

22. Luciano Ozzello, and Speer, F. D.: The mucopolysaccharide in the normal and diseased breast, their distribution and significance. Am. J. Path. 34: 993$1009,1958.1$

23. Muaz Osman Fagare. Evaluation of Mucin Histo-Chemical Pattern in Breast, Colonic, Ovarian and

Lung Adenocarcinomas International Journal of Life Sciences Research ISSN 2348-3148 (online) 2015 Oct-Dec; 3(4):39-46.

24. Spicer S.S, Leppi. T.J and Stoward. P.J. Suggestion of Histochemical terminology of carbohydrate rich tissuecomponents. J. Histochem. Cytochem. 1965;13:599-03.

25. Alan stevans, Bancroft JD, Stevans A. Theory and practice of histological technique. $3 \mathrm{rd}$ ed. Churchill livingstone, New York.1990;107-117

26. Subramanyam C.S.V. Microscope. Guidelines to its intelligent use. Handbook of Workshop on Histopathology Technique And Intelligent Use of Microscope. Belgaum. 1989 :2-4. 